Ventenat! .... Teneriffe / Vahl". Nos lleva esto a pensar que la localidad clásica pueda ser Tenerife y que muy probablemente el pliego que llegó a manos de Vahl tuviese la etiqueta cambiada con otro procedente, en efecto, de Puerto Rico.

Cyperus distans L. fil., Suppl. P1.: 103 (1782)

Kåre A. Lye (Ås, Noruega), a quien agradecemos vivamente su colaboración, determinó con este nombre una imagen digital que le hicimos llegar del pliego de "A Coruña: Negreira; orillas del Tambre, .... cola del embalse, con Bidens tripartita y Polygonum hydropiper, 29TNH2150, 30-IX2000. Leg. J. Amigo"

Según nos dijo el propio recolector, J. Amigo, quien volvió a visitar la localidad en junio de 2005, allí vivían unos 200 pies, distribuidos por una superficie de unos 200 $\mathrm{m}^{2}$. Todos sus intentos de localizarla, visitando embalses y hábitat similares al de Negreira, resultaron fallidos. Suponemos pues que, al menos por ahora, se trata de una primera introducción, en una localidad muy concreta y que no se ha extendido todavía. Como sabemos también que otras especies, introducidas en una ocasión han acabo por desaparecer (cf. C. congestus, citado más arriba), optamos considerarla una alóctona circunstancial, por lo que será mencionada en el apartado Observaciones del género, pero no incluida en la clave, ni numerada, descrita, etc.

Aceptado para su publicación en octubre de 2005

Dirección del autor. Real Jardín Botánico CSIC, Plaza de Murillo 2, 28014 Madrid.

2. ACERCA DE LA IDENTIDAD DE CYPERUS HUMIFUSUS CLEMENTE, ENSAYO VAR. VID ANDALUCÍA: 284 (1807) [CYPERACEAE]

Santiago CASTROVIEJO y Juan ARMADA

La preparación de la síntesis de las especies ibéricas del género Cyperus obligó a revisar todo el material del género conservado en el herbario del Real Jardín Botánico. Allí tropezamos con un pliego que guarda dos pies de planta recolectados por Simón de Rojas Clemente en Bornos (Cádiz), que son, ni más ni menos, que el tipo de su Cyperus humiffussus [sic], publicado en la "lista primera de plantas" del famoso Ensayo sobre las variedades de la vid común que vegetan en Andalucía...

Clemente, una vez hecha la descripción, la compara con Pycreus flavescens (L.)

Trabajo realizado con fondos del proyecto Flora iberica IV (REN2002-04634-CO5-05). 
Rchb. ["Differt à Cypero flavescenti L. culmis debilibus....], lo que probablemente llevó a J.J. Roemer \& J.A. Schultes, cuando escribieron su edición del Systema vegetabilium linneano, a considerarla como una mera variedad de lo que hoy se llama Pycreus flavidus (Retz.) T. Koyama J. Jap. Bot. 51(10): 316 (1976), al proponer la combinación C. globosus var. humifusus (Clemente) Roem. \& Schult., Syst. Veg. 2: 170 (1817). Este nombre sería posteriormente recogido por Willkomm [Willk. \& Lange, Prodr. Fl. Hispan. †1: 137 (1870)], aunque luego no parece haber sido ya muy utilizado.

C. Vicioso, en su incansable tarea de conservador de facto del herbario MA, deja constancia en una etiqueta del nombre utilizado por Willkomm.

Un estudio detallado de los ejemplares nos permite comprobar que el aquenio es trígono y una de sus caras está en contacto con el eje de la espiguilla, lo cual nos lleva a afirmar que no se trata de un Pycreus, sino de un verdadero Cyperus. A juzgar por el hábito de la planta, la forma, tamaño y color de la bráctea, etc. podemos decir que se trata de C. fuscus L., especie frecuente en el área.

Aceptado para su publicación en octubre de 2005

Dirección de los autores. Real Jardín Botánico CSIC. Plaza de Murillo 2, 28014 Madrid

\section{PYCREUS POLYSTACHYOS (ROTTB.) PB., PLANTA AL PARECER, EXTRAPENINSULAR}

Santiago CASTROVIEJO

Pycreus polystachyos (Rottb.) PB., Fl. Oware 2 (1816)

Cyperus polystachyos Rottb., Descr. Icon. Rar Pl.: 39 (1773) [basión]

Especie originaria de África tropical y del E de América, citada en una sola ocasión en nuestra Península, en «Fuente del Plomo, Jalance» (V) [cf. J.B. Peris, Contr. Estud. Fl. Fitosiol. Boquerón y Palmenra 2: 267 (1983)], pero de la que no parece que haya testimonio. A partir de entonces fue incluida en los catálogos o floras locales [Mateo \& Crespo, M.B., Claves Fl. Valencia: 358
(1990) y Bolòs \& Vigo, Fl. Països Catalans 4: 229 (2001)], aunque estos últimos autores (loc. cit.) parecen indicar que no es posible que viva en Valencia, pues no parece soportar las condiciones de un clima subcontinental, algo frío, como el de esa zona. Merola [Delpinoa 10(27): 5-22] cuenta que la única población que subsiste en Europa es la de una isla próxima a Nápoles, porque debido a las fumarolas volcánicas, la temperatura allí no baja de $10^{\circ} \mathrm{C}$ y el suelo no lo hace nunca de $15^{\circ} \mathrm{C}$.

Manuel B. Crespo, por su parte, informa (com. pers.) que ni G. Mateo ni él han visto 